\title{
Purification, characterization, and structural elucidation of serralysin-like alkaline metalloprotease from a novel source
}

\author{
Swathi Nageswara ${ }^{12^{*}}$, Girijasankar Guntuku ${ }^{1}$ and Bhagya Lakshmi Yakkali
}

\begin{abstract}
Background: Serratiopeptidase is an alkaline metalloendopeptidase, which acquired wide significance because of its therapeutic applications. The present study was undertaken for purification, characterization, and structural elucidation of serratiopeptidase produced from Streptomyces hydrogenans var. MGS13.

Result: The crude enzyme was purified by precipitating with ammonium sulfate, dialysis, and Sephadex gel filtration, resulting in 34\% recovery with a $12 \%$ purification fold. The purified enzyme S.AMP13 was spotted as a single clear hydrolytic band on casein zymogram and whose molecular weight was found to be $32 \mathrm{kDa}$ by SDS-PAGE. The inhibitor and stability studies revealed that this enzyme is metalloprotease, thermostable, and alkaline in nature. The maximum serratiopeptidase activity was observed at $37^{\circ} \mathrm{C}$ and $\mathrm{pH} 9.0$. The partial amino acid sequence of the purified enzyme S.AMP13 by LC-MS/MS analysis shows the closest sequence similarities with previously reported alkaline metalloendopeptidases. The amino acid sequence alignment of S.AMP13 shared a conserved C-terminus region with peptidase-M10 serralysin superfamily at amino acid positions 128-147, i.e., ANLSTRATDTVYGFNSTAGR revealed that this enzyme is a serralysin-like protease. The kinetic studies of the purified enzyme revealed a $K_{m}$ of $1 \mathrm{mg} / \mathrm{mL}$ for its substrate casein and $V_{\max }$ of $319 \mathrm{U} /$ $\mathrm{mL} / \mathrm{min}$. The 3D structure of the purified enzyme was modeled by using SWISS-MODEL, and the quality of the structure was authenticated by assessing the Ramachandran plot using PROCHECK server, which suggested that the enzyme was stable with good quality.
\end{abstract}

Conclusion: Inhibitor, stability, electrophoretic, and bioinformatic studies suggested that the purified enzyme obtained from S. hydrogenans var. MGS13 is a serralysin-like protease.

Keywords: Purification, Characterization, Streptomyces hydrogenans var. MGS13, Metalloendopeptidases, Partial amino acid sequence, Serralysin

\section{Background}

Peptidases are hydrolases that catalyze the hydrolysis of peptide and iso-peptide bonds that join amino acids within proteins, and based on the catalytic mechanism, peptidases are classified as metalloserine, aspartic, cysteine, and threonine [1]. Among these proteases, metalloproteases represent the largest class of hydrolases that usually contain divalent metal ions at an active site which plays an important role in proteolysis.

\footnotetext{
* Correspondence: swathinageswara@gmail.com

${ }^{1}$ A.U. College of Pharmaceutical Sciences, Andhra University, Visakhapatnam, Andhra Pradesh 530003, India

${ }^{2}$ Srikakulam, India
}

Serratiopeptidase (EC 3.4.24.40) also known as serrapeptase and serralysin, which is a type of metalloendopeptidase, possess anti-edemic, anti-inflammatory analgesic, fibrinolytic, and anti-atherosclerotic properties and have been directly employed in clinical therapy in regulation of inflammation and pain, and furthermore, serrapeptase is even being used as a health supplement to protect the heart from atherosclerosis, which was achieved by degradation of atherosclerotic plaque and fibrin on the inside of arteries [2]. The anti-inflammatory and analgesic activity of serratiopeptidase is achieved by degrading the inflammationcausing amino acid derivatives such as histamine, serotonin, and bradykinin [3]. Serratiopeptidase is an alkaline metallopeptidase originally isolated from Serratia 
marcescens; later homolog of this enzyme was also reported from some genera of gram-negative and positive bacteria, such as Pseudomonas aeruginosa, Proteus mirabilis, Erwinia chrysanthemi [4, 5], Xenorhabdus [6, 7], Deinococcus radiodurans [8], and Bacillus subtilis [9]. Serralysin contains one atom of zinc per molecule as an essential element indicating that serralysin family belongs to the metzincin class of proteases according to the MEROPS database [10]. Presently, serratiopeptidase obtained from Serratia E-15, an opportunistic pathogen, is being used in therapy for inflammation; due to its pathogenicity, the enzyme has been reported to cause lung and corneal damage [11]. This problem has necessitated screening of new microbial strains for producing the serratiopeptidase from novel sources with better therapeutic potential and desirable characters.

Streptomyces has gained attention in the present decade due to the discovery of various fibrinolytic enzymes (plasmin-like [12], serine-like [13], and chymotrypsin-like serine-metallo fibrinolytic enzymes) [14]. Furthermore, Jyothi et al. earlier isolated a serratiopeptidase-producing organism in our laboratory, identified as Streptomyces hydrogenans var. MGS13 [15], which was used for the production of serratiopeptidase by submerged fermentation technology [16]. Increasing attention is being given to the production of microbial metabolites by solid-state fermentation (SSF) as it has many advantages over submerged fermentation. Hence, in the present study, SSF was selected for the production of serratiopeptidase from $S$. hydrogenans var. MGS13. Purification of enzymes is a challenging and essential step for identifying the enzymes with their structure-functional properties, and the role of purification is to achieve the utmost possible purity and yield of the desired enzyme with the maximum catalytic activity. The combination of two-dimensional (2D) gel electrophoresis and peptide mass fingerprinting analysis by mass spectrometry is a widely used strategy in proteomics study over traditional method where proteins were identified by de novo sequencing using automated Edman degradation method [17].

The present work throws light on the purification and characterization of serralysin-like enzyme with respect to the peptide mapping by LC-MS/MS for its partial amino acid sequence alignment, followed by structural elucidation using various bioinformatic tools.

\section{Methods}

\section{Design of the study}

The new strain Streptomyces hydrogenans var. MGS13 isolated from Koringa mangrove soil was used in the present study for the production of serratiopeptidase by solid-state fermentation. The enzyme was purified by employing ammonium sulfate precipitation, followed by dialysis and gel filtration. Further characterization was done by performing stability and inhibitor studies. Finally, a combination of 2D gel electrophoresis, mass spectrometry, and bioinformatic tools was used for structural elucidation of purified serratiopeptidase.

\section{Serratiopeptidase production}

Serratiopeptidase was obtained from S. hydrogenans var. MGS13 using optimized medium composed of horse gram (4.8 g; particle size $600-250 \mu \mathrm{m})$, soya bean $1.1 \%$, initial moisture content $42 \%$ and sterilized at $121^{\circ} \mathrm{C}$ at $15 \mathrm{lbs}$ pressure for $20 \mathrm{~min}$. After cooling, $1.2 \mathrm{~mL}$ of inoculum was added and incubated at $28^{\circ} \mathrm{C}$ for 4 days then the crude enzyme was obtained by extracting with sodium borate buffer ( $\mathrm{pH} 9.0$ ).

\section{Determination of serratiopeptidase activity and protein content}

Quantitative estimation of serratiopeptidase activity was determined according to IP 2010 [18]. One unit of serratiopeptidase was defined as the amount of enzyme required to liberate $1 \mu \mathrm{m}$ of free tyrosine per min under standard assay conditions. Protein content was quantified according to the Lowry method [19] using bovine serum albumin as a protein standard.

\section{Purification of serratiopeptidase produced from $S$. hydrogenans var. MGS13}

An attempt was made to decide the optimal concentration required for the precipitation of the enzyme. For this purpose, various concentrations of ammonium sulfate were supplemented to the supernatant to attain $40-80 \%$ saturation. The precipitated proteins were redissolved in minimum quantity of sodium borate hydrochloric acid buffer $\mathrm{pH} 9.0$ and dialyzed using dialysis membrane-50 (HiMedia-cutoff value $12 \mathrm{kDa}$ ) against the same borate buffer overnight at $4{ }^{\circ} \mathrm{C}$. Then, the sample was concentrated, desalted, and loaded on the Sephadex G-100 column $(30 \times 1.8 \mathrm{~cm})$ for purification. The enzyme fractions were eluted using sodium borate buffer $\mathrm{pH} 9.0$ with a flow rate of $0.3 \mathrm{~mL} / \mathrm{min}$. The fractions eluted from the gel filtration column were tested for serratiopeptidase activity and total protein content. The fractions having enzyme activity were pooled, concentrated, and used as a purified sample for all the characterization studies. The recovery of enzyme and purification fold was calculated in terms of specific activity.

\section{Electrophoretic analysis}

The molecular weight of the purified protease was analyzed by SDS-PAGE according to the Laemmli method [20] using $15 \%$ polyacrylamide resolving gel. The mass was ascertained by comparing with pre-stained known 
Table 1 Summary of the purification of protease from S. hydrogenans var. MGS13

\begin{tabular}{llllll}
\hline Purification stages & Total protein $(\mathrm{mg})$ & Total enzyme activity units & Specific activity (U/mg) & Purification fold & Recovery (\%) \\
\hline Cell-free supernatant & 12,460 & 51,670 & 4 & 1 & 100 \\
50\% ammonium sulfate precipitation & 840 & 27,230 & 30 & 7 & 52 \\
Dialyzed sample & 770 & 22,200 & 40 & 9.7 & 43 \\
Sephadex G-100 & 370.25 & 17,500 & 50 & 12 & 34 \\
\hline
\end{tabular}

molecular weight markers ranging from 10 to $245 \mathrm{kDa}$, HiMedia.

Casein zymography of purified serratiopeptidase was performed according to the Garcia-Carreno method [21] using casein $(0.2 \% \mathrm{w} / \mathrm{v})$ as a substrate in $15 \%$ resolving gel. The sample was dissolved in non-reducing SDS-loading buffer without heating. Subsequent to electrophoresis, the gel was kept for $1 \mathrm{~h}$ for incubation in $100 \mathrm{~mL}$ of sodium borate buffer $\mathrm{pH} 9.0$ containing $2.5 \%(v / v)$ Triton X-100 to remove SDS and thoroughly rinsed with double distilled water to remove Triton X100. Then, the gel was incubated in a buffer for an hour and later stained with 0.025\% Coomassie Brilliant Blue $\mathrm{R}-250$ and de-stained.

\section{Effect of $\mathrm{pH}$ on serratiopeptidase stability and activity}

The influence of $\mathrm{pH}$ on serratiopeptidase stability was determined by exposing the purified serratiopeptidase to various $\mathrm{pH}$ buffers of $50 \mathrm{mM}$ concentration at $37^{\circ} \mathrm{C}$ for $1 \mathrm{~h}$, and the residual serratiopeptidase activity was measured. The buffers used for this study were phosphate buffer $\mathrm{pH}$ 4.0, 5.0, 6.0, 7.0, and 8.0; borate buffer $\mathrm{pH} 9.0$ and 10.0; and glycine buffer 11.0. Optimum $\mathrm{pH}$ for serratiopeptidase activity was determined by preparing the substrate (casein) in the above buffers, and serratiopeptidase activity was measured as mentioned earlier.

\section{Effect of temperature on serratiopeptidase stability and activity}

The influence of temperature on serratiopeptidase stability was determined by incubating the purified protease at various temperatures $20^{\circ} \mathrm{C}, 28^{\circ} \mathrm{C}, 37^{\circ} \mathrm{C}, 50^{\circ} \mathrm{C}$, and $60^{\circ} \mathrm{C}$ for $1 \mathrm{~h}$ in sodium borate buffer at $\mathrm{pH} 9.0$, followed by serratiopeptidase assay, whereas, the optimum temperature for serratiopeptidase activity was measured by performing the assay at diverse temperatures ranging from $20^{\circ} \mathrm{C}, 28^{\circ} \mathrm{C}, 37^{\circ} \mathrm{C}, 50^{\circ} \mathrm{C}$, and $60^{\circ} \mathrm{C}$ for $30 \mathrm{~min}$ in sodium borate buffer of $\mathrm{pH}$ 9.0.

\section{Effect of inhibitors on enzyme activity}

The influence of chelating agents such as ethylene diamine tetra acetic acid (EDTA) and phenyl methyl sulfonyl fluoride (PMSF) on the activity of serratiopeptidase was determined by incubating the purified enzyme with $1 \mathrm{mM}, 5 \mathrm{mM}$, and $10 \mathrm{mM}$ concentrations of EDTA and
PMSF solutions for $30 \mathrm{~min}$ at $37^{\circ} \mathrm{C}$, and the comparative activities were obtained by performing serratiopeptidase assay. The activity of the control (purified enzyme without any inhibitor) was determined and considered as $100 \%$. The influence of chelating agents on the enzyme activity was also determined by casein clearing zone technique [22]. The purified enzyme S.AMP13 was incubated with inhibitors at concentrations of $1 \mathrm{mM}, 5 \mathrm{mM}$, and $10 \mathrm{mM}$ for $30 \mathrm{~min}$ at $37^{\circ} \mathrm{C}$ and introduced into wells of casein agar plate after $24 \mathrm{~h}$ incubation; the activities were assessed by measuring the clearing zone.

\section{Effect of metal ions}

The serratiopeptidase activity was assessed before and after the inactivation of metal ions from purified protease using $10 \mathrm{mM}$ EDTA. In order to study the influence of metal ions on enzyme activity before chelation, the purified enzyme $(1 \mathrm{mg} / \mathrm{mL})$ was incubated for a time interval of $1 \mathrm{~h}$ at $37^{\circ} \mathrm{C}$ with different metal ions at a concentration of $5 \mathrm{mM}$ of $\mathrm{Mg}^{+2}, \mathrm{Zn}^{+2}, \mathrm{Ca}^{+2}$, $\mathrm{Cu}^{+2}, \mathrm{Na}^{+}$, and $\mathrm{K}^{+}$in $50 \mathrm{mM}$ of sodium borate buffer $\mathrm{pH}$ 9.0, and serratiopeptidase activity was determined as described earlier. For analyzing the metal ion effect after chelation, the purified enzyme was incubated

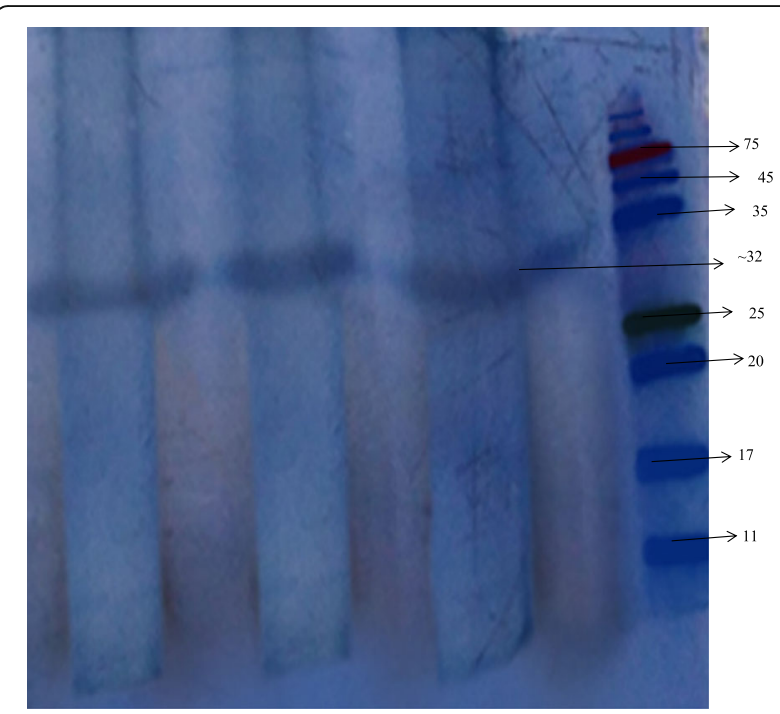

Fig. 1 SDS-PAGE of purified serratiopeptidase. The molecular mass of purified serratiopeptidase was determined by comparing with protein markers 


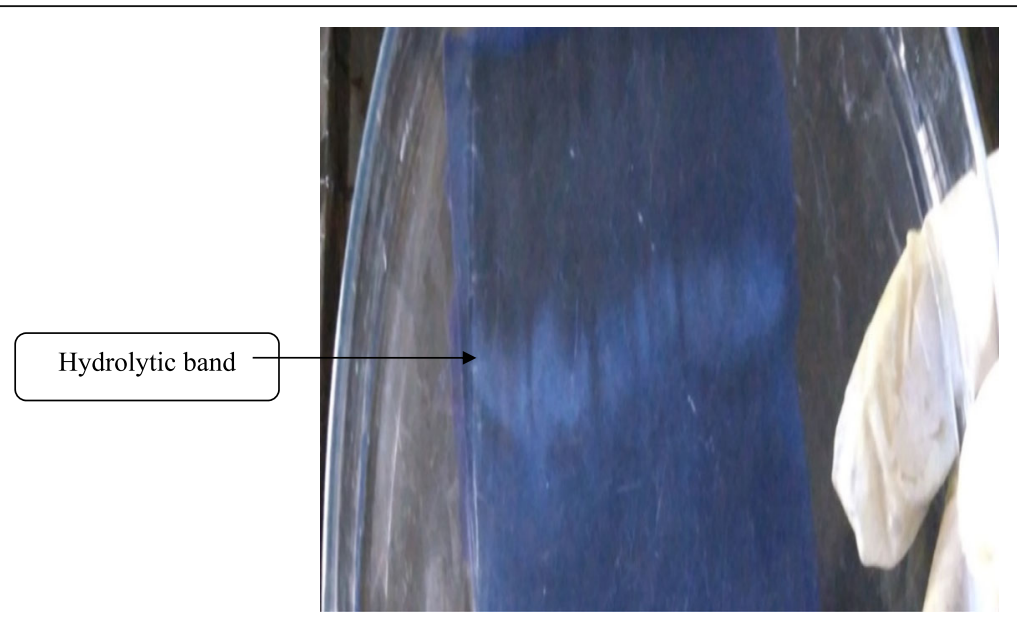

Fig. 2 Casein zymogram of purified serratiopeptidase. Purified serratiopeptidase showing a clear hydrolytic band on casein polymerized gel

with $10 \mathrm{mM}$ EDTA, followed by incubation with different metal ions in sodium borate buffer $50 \mathrm{mM}$ ( $\mathrm{pH} 9.0$ ) at $37^{\circ} \mathrm{C}$ for $1 \mathrm{~h}$, and the samples were evaluated by performing the serratiopeptidase assay. The activity of purified serratiopeptidase in a buffer without a chelating agent and metal ions (control) was assessed.

\section{Determination of kinetic parameters}

The kinetic constants of the purified enzyme were determined by measuring the serratiopeptidase activity at different casein (substrate) concentrations (1.2 to $9.8 \mathrm{mg} / \mathrm{mL}$ ).
The $K_{m}$ and $V_{\max }$ values were determined using the Michaelis-Menten graph, and the Lineweaver-Burk doublereciprocal graph was plotted with calculated values.

\section{Analysis of amino acid sequence}

The purified enzyme was excised from the SDS-PAGE gel as a single protein band and named as S.AMP13 and dehydrated. After drying, the gel pieces were reduced with $10 \mathrm{mM}$ dithiothreitol (DTT) in $100 \mathrm{mM}$ ammonium bicarbonate, incubated at $56^{\circ} \mathrm{C}$ for an hour and alkylated by incubating with iodoacetamide for $45 \mathrm{~min}$ at room temperature, then digested by

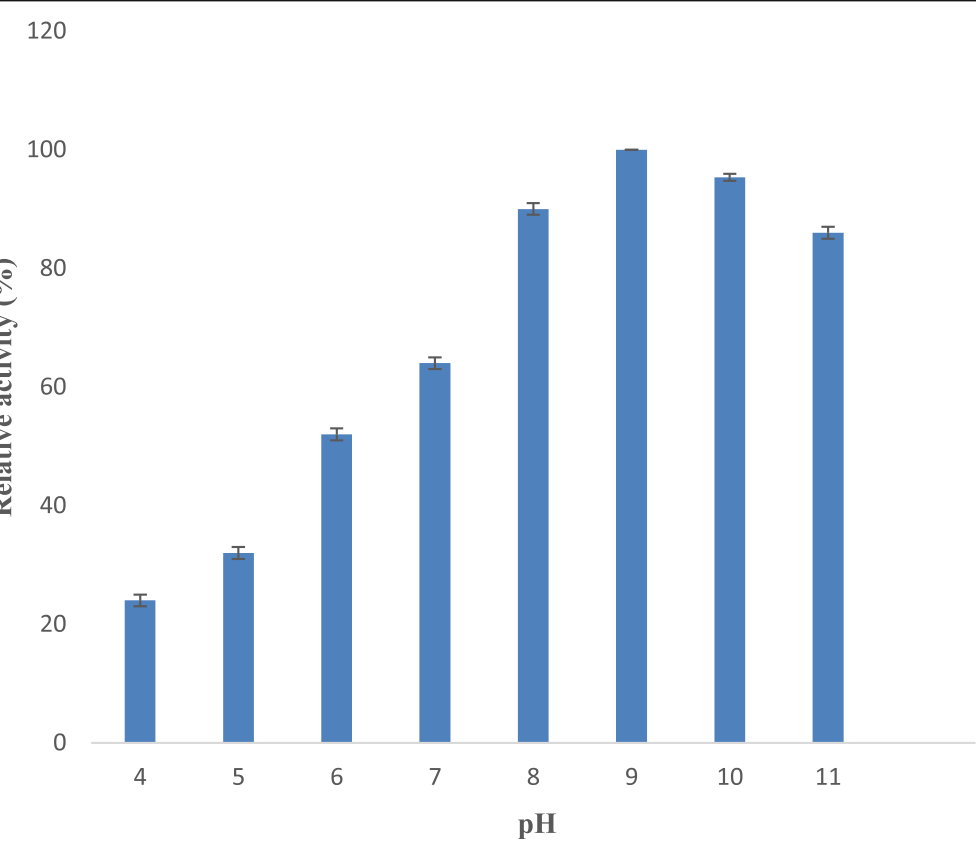

Fig. 3 Effect of pH on serratiopeptidase activity. The enzyme activity was measured at various $\mathrm{pH}$ (4 to 11) using a standard assay method. Each value represents the mean \pm SD for three determinations 


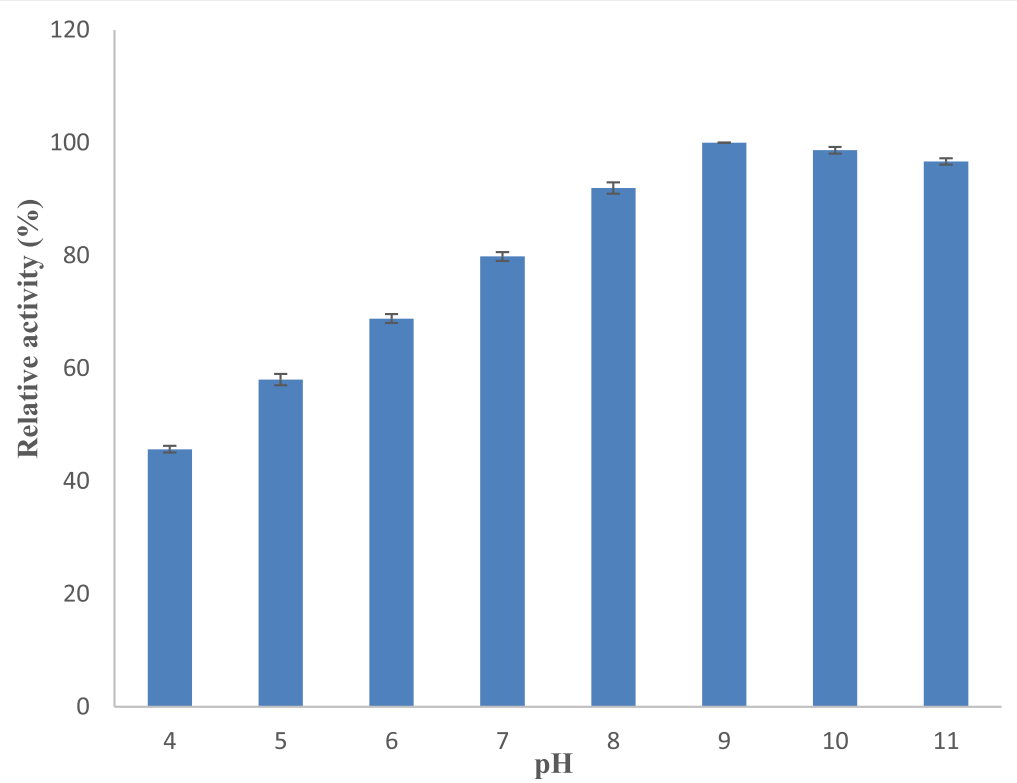

Fig. 4 Effect of pH on serratiopeptidase stability. The enzyme stability was measured at various pH (4 to 11) using a standard assay method. Each value represents the mean \pm SD for three determinations

incubating with trypsin solution overnight at $37^{\circ} \mathrm{C}$. The resulting tryptic digested peptides were extracted, and the supernatant was dispensed into an autosampler vial for peptide analysis by LC-MS. The tryptic digested peptides of $10-\mu \mathrm{L}$ sample were injected in $\mathrm{C}_{18}$ UPLC column $(75 \mu \mathrm{m} \times 150 \mathrm{~mm}), 1.7-\mu \mathrm{m}$ particle size for the separation of peptides using a Water ACQUITY UPLC system, followed by analysis on the Q-TOF (model-Synapt G2) instrument for MS and MSMS. The column was eluted with a flow rate of
$0.3 \mathrm{~mL} / \mathrm{min}$ using buffers A $(0.1 \%$ by volume formic acid (FA) in water) and $\mathrm{B}(0.1 \%$ by volume formic acid in acetonitrile $(\mathrm{ACN})$ ). The raw data was processed by Mass Lynx 4.1 Waters, peptide editor software, to get the complete integrated sequence of the sample. The individual peptide MSMS spectra were matched to the database sequence for amino acid sequence, and protein identification was assigned by searching a Swiss-Prot database containing all known alkaline metalloprotease from Streptomyces and other

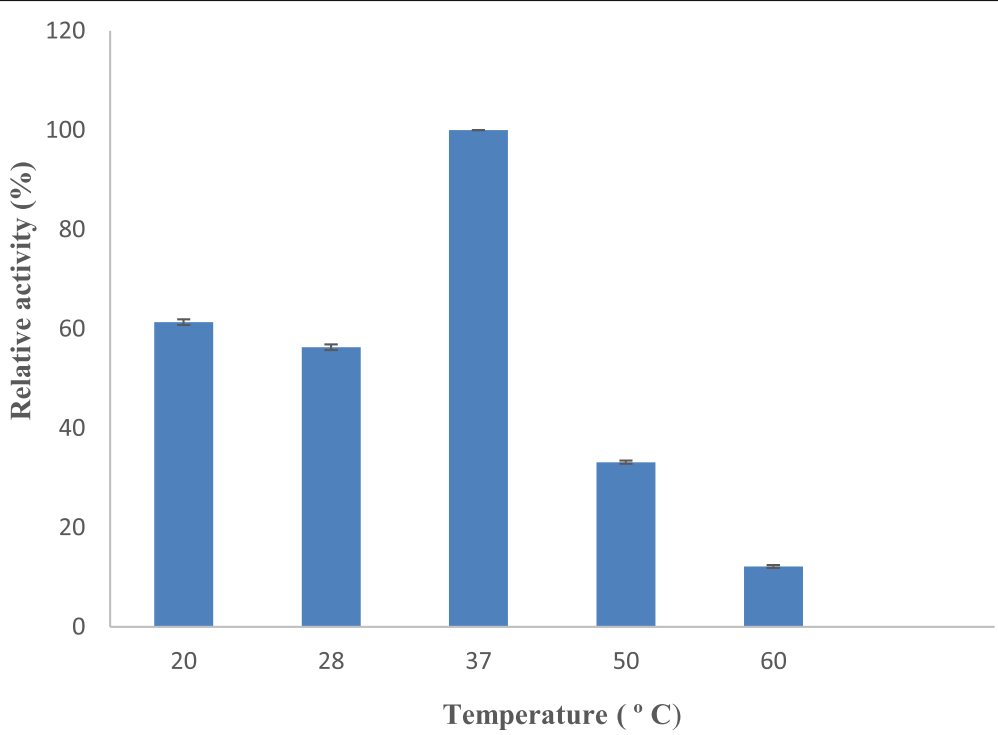

Fig. 5 Effect of temperature on serratiopeptidase activity. The enzyme activity was measured at different temperatures $\left(20^{\circ} \mathrm{C}, 28^{\circ} \mathrm{C}, 37^{\circ} \mathrm{C}, 50^{\circ} \mathrm{C}\right.$, and $60^{\circ} \mathrm{C}$ ) using a standard assay method. Each value represents the mean \pm SD for three determinations 


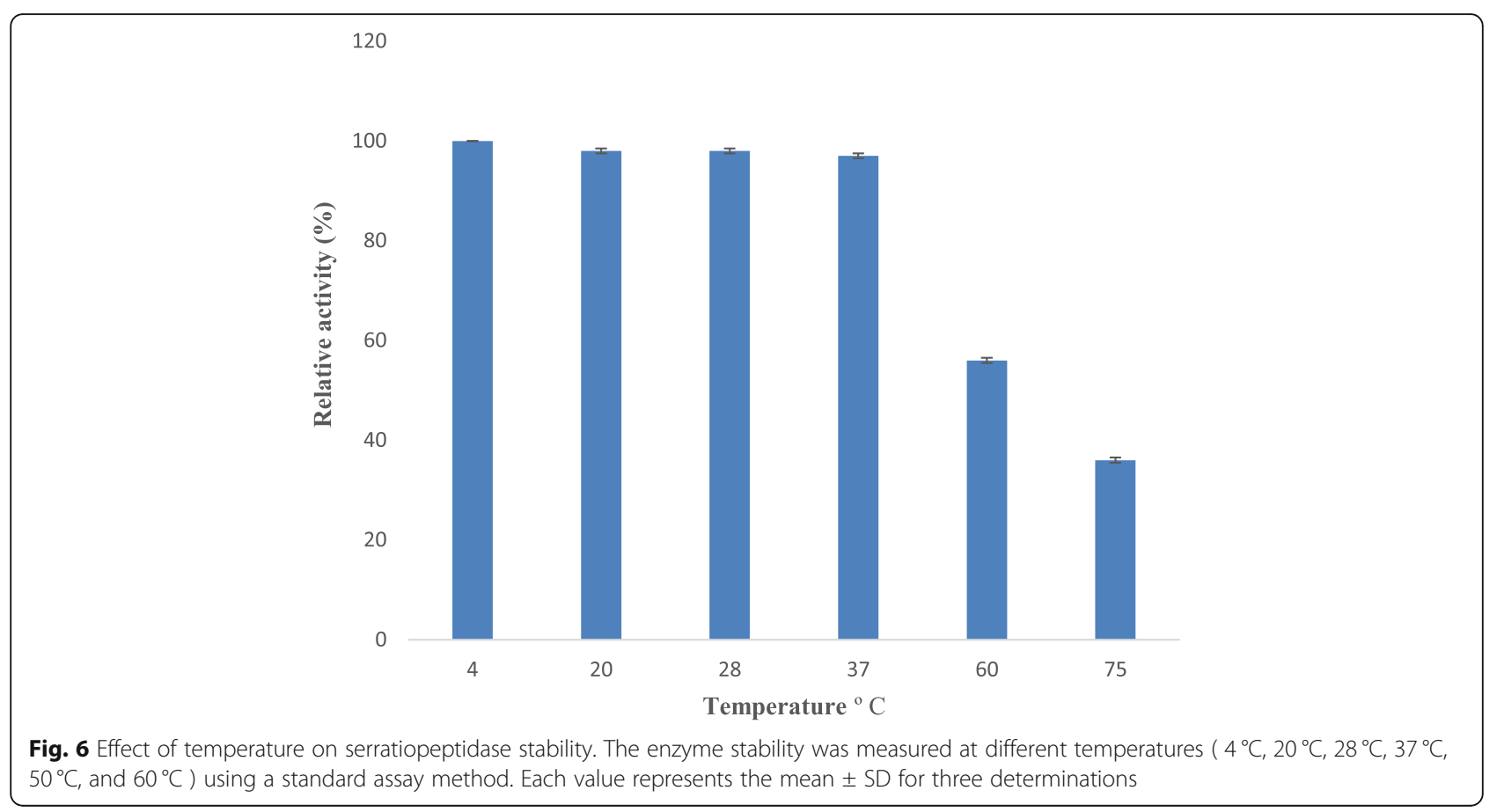

bacterial sources based on ProteinLynx Global SERVER (PLGS) score software, Waters. The obtained protein sequence was aligned with the similar proteins using "Clustal X2" [23] for the construction of pairwise sequence alignment from the sequence set. A dendrogram (guide tree) was constructed to analyze the phylogenetic relation of the newly identified protein by neighborjoining (NJ) statistical method using MEGA 6.06 (Molecular Evolutionary Genetics Analysis) software. Conserved domain and motif in the sequence were identified using the conserved domain database of NCBI (https://www.ncbi. nlm.nih.gov/Structure/cdd/wrpsb.cgi) and motif scan (http://myhits.isb-sib.ch/cgibin/motif_scan).

\section{Prediction of structure}

SWISS-MODEL server (http://swissmodel.expasy.org/interactive) was used to predict the 3D structure of the designed protein based on homology or comparative modeling, and the templates with the highest quality have been selected

Table 2 Effect of inhibitors on serratiopeptidase activity

\begin{tabular}{lll}
\hline Sample & Concentration $(\mathrm{mM})$ & Serratiopeptidase activity \\
\hline Control & - & $100 \%$ \\
EDTA & 1 & $55 \% \pm 0.3$ \\
& 5 & $42 \% \pm 0.2$ \\
& 10 & $39 \% \pm 0.4$ \\
PMSF & 1 & $80 \% \pm 0.5$ \\
& 5 & $72 \% \pm 0.6$ \\
& 10 & $70 \% \pm 0.5$
\end{tabular}

Each value represents the mean \pm SD for three determinations for model building. The best model was selected based on the QMEAN score. The computed model was structurally validated and analyzed by using PROCHECK of the PDBsum server, and the secondary structure and functions of protease were predicted using ProFunc server.

\section{Results}

\section{Purification of serratiopeptidase}

Serratiopeptidase produced by $S$. hydrogenans var. MGS13 was partially purified by precipitating the supernatant with different concentrations of ammonium sulfate to attain a maximum saturation. Among them, 50\% saturation level yielded a maximum recovery of $52 \%$ partially purified protease suggesting $7 \%$ fold purification. The precipitated enzyme was resuspended in sodium borate hydrochloric acid buffer $\mathrm{pH} 9.0$ and further dialyzed against the same buffer using $12-\mathrm{kDa}$ cutoff membrane. This step yielded 9.7\% fold purification with a specific enzyme activity of 40.3 units $/ \mathrm{mg}$ of protein. Then, the partially purified enzyme was applied on Sephadex G-100 column for filtration, and active fractions showing serratiopeptidase activity were pooled. The specific activity of the final enzyme preparation was $50 \mathrm{U} / \mathrm{mg}$ of protein (Table 1 ).

Table 3 Effect of various inhibitors on purified protease

\begin{tabular}{lll}
\hline Inhibitors & Concentration $(\mathrm{mM})$ & Average of zone diameter $(\mathrm{cm})$ \\
\hline Control & - & 2.6 \\
PMSF & 5 & 2.6 \\
EDTA & 5 & 2.0 \\
\hline
\end{tabular}

EDTA ethylene diamine tetra acetic acid, PMSF phenyl methyl sulfonyl fluoride 


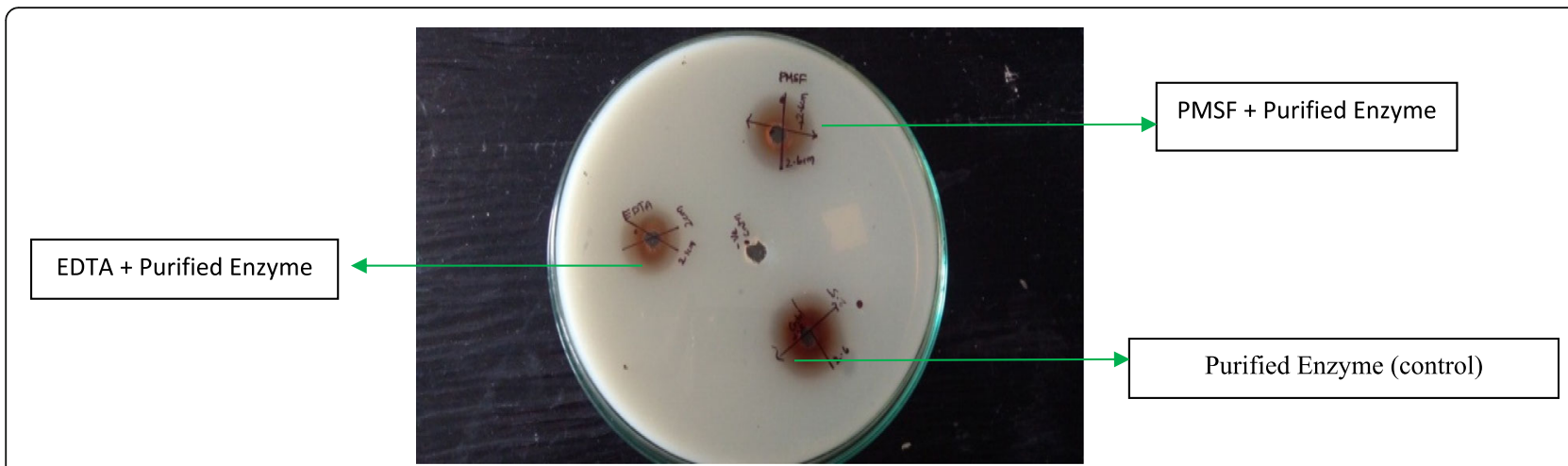

Fig. 7 Effect of various inhibitors on purified protease. The inhibitors' role was determined by measuring the casein hydrolytic zone after the preincubation of the enzyme with inhibitors. Control, purified enzyme without inhibitors; EDTA, ethylene diamine tetra acetic acid; PMSF, phenyl methyl sulfonyl fluoride

Overall, $12 \%$ fold purification and recovery of $34 \%$ yield were obtained at the end of purification steps.

\section{Electrophoresis techniques}

The observed single band in SDS-PAGE shows that the purified enzyme is homogenous with a molecular mass of $32 \mathrm{kDa}$ (Fig. 1). Casein zymography also exhibited a single clear hydrolyzed band indicating that the purified protein is a "proteolytic enzyme" (Fig. 2).

\section{Enzyme characterization}

\section{Effect of $\mathrm{pH}$ on serratiopeptidase activity and stability}

Comparative activities of serratiopeptidase in various $\mathrm{pH}$ buffers have been measured, and maximum activity exhibited by the protease in buffer with $\mathrm{pH} 9.0$ has been considered as $100 \%$ (Fig. 3). A very low activity (24\%) was noted at $\mathrm{pH} 4.0$, followed by $\mathrm{pH} 5.0$ (32\%), 6.0 (52\%), and 7.0 (64\%) which demonstrates that the enzyme is neither acidic nor neutral protease.

Figure 4 shows the residual activities of serratiopeptidase in different $\mathrm{pH}$ buffers, and the purified protease of S. hydrogenans var. MGS13 showed greater than 50\% serratiopeptidase activity at $\mathrm{pH} 7.0-10.0$ after 1 -h incubation period; the activity was substantially reduced below pH 7.0 and remains constant over 10.0.

\section{Effect of temperature on serratiopeptidase activity and stability}

Comparative activities of serratiopeptidase at different temperatures have been measured, and maximum activity showed by the protease at $37^{\circ} \mathrm{C}$ has been considered as $100 \%$ (Fig. 5). At $28^{\circ} \mathrm{C}$ and $20^{\circ} \mathrm{C}$, the observed comparative activities were found to be $70 \%$ and $61 \%$, respectively, and very low comparative activities of $33 \%$ and $12 \%$ were observed at $50{ }^{\circ} \mathrm{C}$ and $60^{\circ} \mathrm{C}$, respectively.

Figure 6 shows the residual activities of protease obtained from S. hydrogenans var. MGS13 at different temperatures, and the serratiopeptidase activity prior to the incubation was evaluated and maximum activity was considered as "cent percent." The purified protease was stable at $4{ }^{\circ} \mathrm{C}$, and $56 \%$ residual activity (Fig. 6) was observed at $60^{\circ} \mathrm{C}$ even after $30 \mathrm{~min}$ incubation.

Table 4 Effect of metal ions on serratiopeptidase activity

\begin{tabular}{lll}
\hline Metal ions (5 mM) & $\begin{array}{l}\text { Relative activity before chelation } \\
\text { and incubation with metal ions (\%) }\end{array}$ & $\begin{array}{l}\text { Regaining enzyme activity after chelation } \\
\text { with EDTA and incubation with metal ions (\%) }\end{array}$ \\
\hline Control & 100 & - \\
Enzyme + EDTA (10 mM) & - & $12 \pm 0.8$ \\
$\mathrm{Ca}^{2+}$ & $138 \pm 1.7$ & $68 \pm 1.6$ \\
$\mathrm{Mg}^{2+}$ & $92 \pm 0.9$ & $18 \pm 1.0$ \\
$\mathrm{Zn}^{2+}$ & $109 \pm 1.5$ & $40 \pm 1.4$ \\
$\mathrm{Cu}^{2+}$ & $98 \pm 1.1$ & $19 \pm 1.0$ \\
$\mathrm{Na}^{+}$ & $105 \pm 1.4$ & $36 \pm 1.3$ \\
$\mathrm{~K}^{+}$ & $102 \pm 1.3$ & $27 \pm 1.1$ \\
\hline
\end{tabular}

Each value represents the mean \pm SD for three determinations 


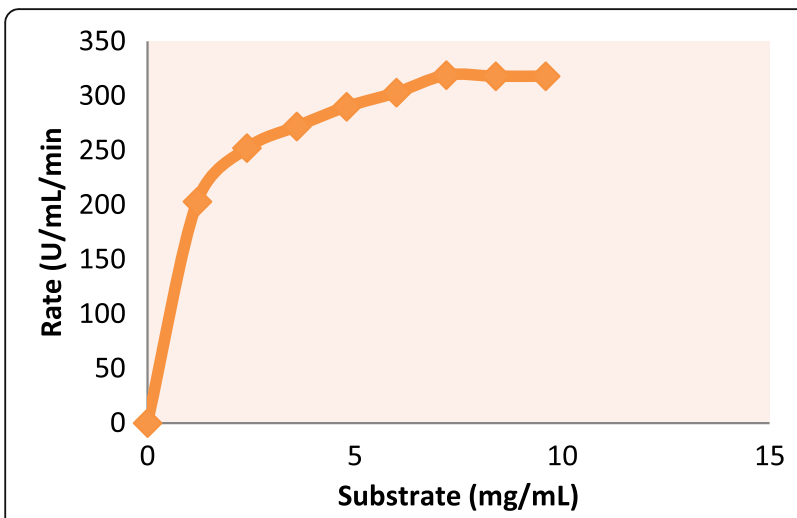

Fig. 8 Michaelis-Menten plot of purified serratiopeptidase

\section{Effect of inhibitors}

Serratiopeptidase activity shown by control (enzyme without inhibitors) was considered as $100 \%$ (Table 2), and activities after incubation with different inhibitors have been expressed relative to the control. The maximum inhibition of serratiopeptidase activity was noticed with $10 \mathrm{mM}$ EDTA. Inhibitor studies by casein clear zone method also suggested that it is a metalloprotease, where a small clear zone $(2 \mathrm{~cm})$ was observed with $5 \mathrm{mM}$ EDTA when compared to that of control (without inhibitor) and PMSF. The concentrations and zone diameters are shown in Fig. 7 and Table 3

\section{Effect of metal ions on enzyme activity before and after chelation with EDTA}

The role of metal ion on the catalytic activity of the enzyme was reckoned by adding $10 \mathrm{mM}$ concentration of metal ion to the reaction mixture. At first, these investigations were carried out to know the role of the added metal ion in the regulation of serratiopeptidase activity. As a control, serratiopeptidase activity in the absence of these metal ions was considered as $100 \%$, and any variation noticed due to the existence of these metal ions was considered as a metal ion-mediated activity. The data indicated that maximum serratiopeptidase activity of $138 \%$ was observed with $\mathrm{Ca}^{2+}$ followed by $\mathrm{Zn}^{2+}, \mathrm{Na}^{+}$, and $\mathrm{K}^{+}$whereas the presence of metals like $\mathrm{Mg}^{2+}$ and $\mathrm{Cu}^{2+}$ in the reaction mixture retarded the catalytic activity.

The specific role of metal ion on the catalytic activity of purified protease obtained from S. hydrogenans var. MGS13 was ascertained by incubating the enzyme with $10 \mathrm{mM}$ EDTA for chelation and followed by measuring the enzyme activity profile by supplementation of different selected metal ions at a concentration of $5 \mathrm{mM}$. Serratiopeptidase activity without the addition of EDTA and any metal salt was considered as $100 \%$ (control), and alteration observed after the addition of metal ion was considered as metal ion effect. In Table 4 , it is conspicuous that the addition of EDTA resulted in a drastic reduction of serratiopeptidase activity and it was observed to be $12 \%$ after chelation with $10 \mathrm{mM}$ EDTA, and the addition of metal ion to the same reaction mixture resulted in recovering the activity but this reactivation was metal ion-specific. A maximum of $68 \%$ enzyme activity was recovered with $\mathrm{Ca}^{2+}$ followed by $\mathrm{Zn}^{2+}(40 \%), \mathrm{Na}^{+}(36 \%)$, and $\mathrm{K}^{+}$(27\%), while less than $20 \%$ activity was recovered with other metal ions such as $\mathrm{Mg}^{2+}(18 \%)$ and $\mathrm{Cu}^{2+}(19 \%)$

\section{Enzyme kinetic studies}

The effect of changing the substrate concentration on serratiopeptidase activity revealed that it follows Michelis-Menten curve (Fig. 8). It was noticed that this protease showed $K_{m}$ of $1 \mathrm{mg} / \mathrm{mL}$ for its substrate casein and $V_{\max }$ of $319 \mathrm{U} / \mathrm{mL} / \mathrm{min}$. The LineweaverBurk(Fig. 9) double graph was plotted with the

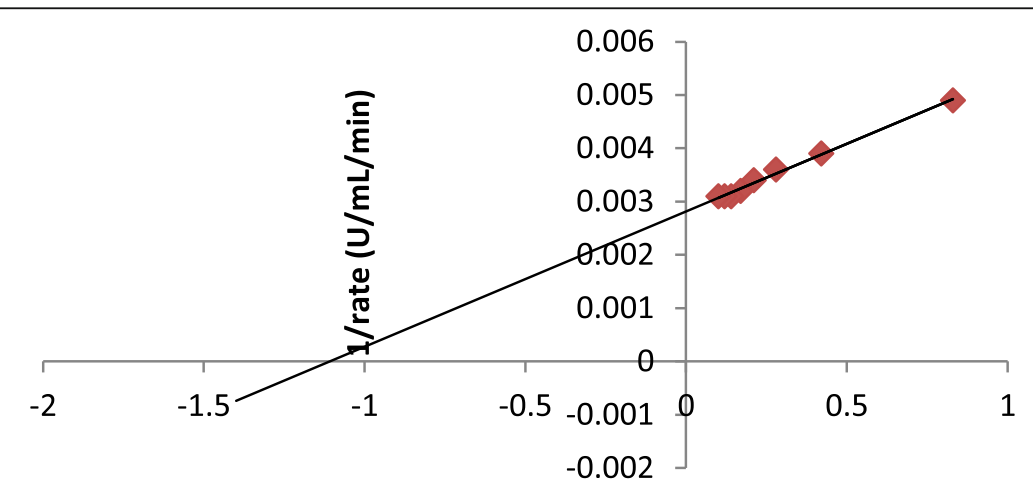

$1 /$ substrate $(\mathrm{mg} / \mathrm{mL})$

Fig. 9 Lineweaver-Burk plot of purified serratiopeptidase 
reciprocal of reaction velocity $(1 / v)$ as a function of reciprocal of substrate concentration $(1 / S)$.

\section{Peptide mapping by mass spectrometry}

The concerned protein of interest was isolated typically by SDS-PAGE and digested with trypsin to generate peptides further separated. The base peak intensities of each peptide fragments (Fig. 10) were analyzed by using LC-MS/MS, and the integrated sequence of the sample was obtained by processing with MassLynx 4.1 Waters, peptide editor software. The individual peptide MSMS spectra were matched to the database sequence for amino acid sequence, and protein S.AMP13 was confidently identified as alkaline metalloprotease based on ProteinLynx Global SERVER software WATERS (licensed software). The false discovery rate for the identification of peptides is $4 \%$. The six trypsin-digested peptide fragment sequences of S.AMP13 matched with 33.7-kDa alkaline metalloendoprotease of Pseudomonas syringae pv. maculicola of Swiss-Prot database (KPB92383.1) with a sequence coverage of $46 \%$ and PLGS score of 139 (Table 5).

Phylogenetic (Fig. 11) analysis of predicted protease S.AMP13 showed the relatedness towards the alkaline metalloendoprotease of Pseudomonas (Accession no. KPB92383.1) as they formed a single cluster.

The partial amino acid sequence of purified protease (S.AMP13) shared a conserved region with superfamily peptidase M10-C terminal at amino acid positions at 128-147, i.e., ANLSTRATDTVYGFNSTAGR indicating that this enzyme (S.AMP 13) might be a serralysin-like metalloprotease as shown in Figs. 12 and 13.

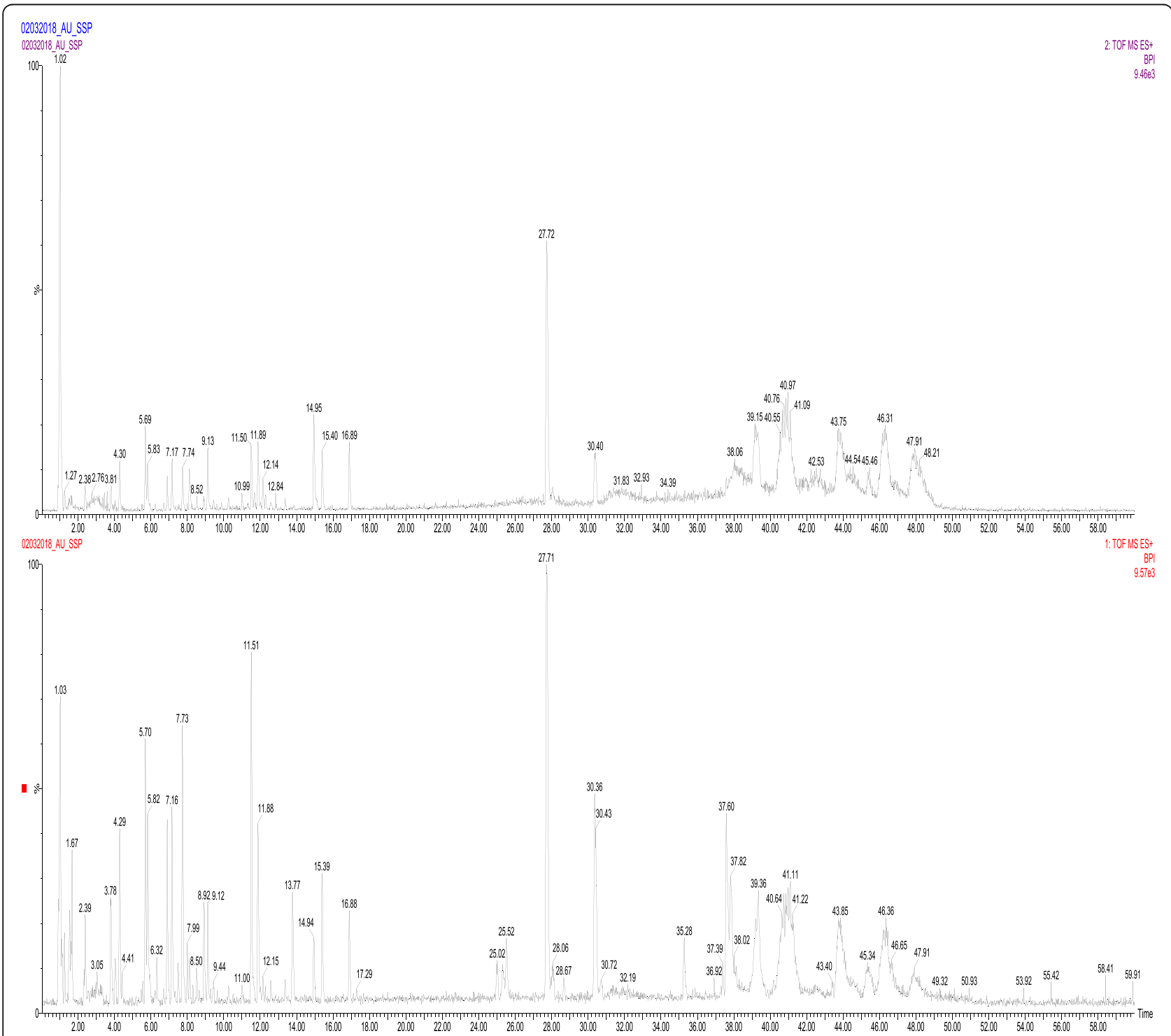

Fig. 10 QTOF-MS of base peak intensity chromatograms of S.AMP13 from S. hydrogenans var. MGS13 
Table 5 Peptide matching of S.AMP13 with alkaline metalloprotease from Pseudomonas syringae pv.maculicola (Accession no. KPB92383.1)

\begin{tabular}{llc}
\hline Positions & Peptide sequence & Peptide M.W (Da) \\
\hline $3-31$ & VKENAAIQLSAATSTSFDQINTFAHEYDR & 3227.56 \\
$5-54$ & ENAAIQLSAATSTSFDQINTFAHEYDRGGNLTINGKPSYSVDQAANFILR & 5416.647 \\
$55-97$ & DDAAWADRDGNGTINLTYTFLTAKPAGFNNALGTFSAFNAQQK & 4593.207 \\
$205-213$ & DATYAEDTR & 1041.448 \\
$233-251$ & GGAPSYSSAPLLDDIAAVQQLYGANLSTR & 2935.48 \\
$262-275$ & ATDTVYGFNSTAGR & 1459.681 \\
\hline
\end{tabular}

Protein structure was predicted by homology modeling using a server like "SWISS-MODEL." Sequence analysis revealed that S.AMP13 showed a maximum percent identification (55.88\%) and sequence coverage with the alkaline metalloprotease template [1jiw.1.A]. Therefore, it was employed as a template for the 3D model prediction of S.AMP13 as shown in Fig. 14, and the model was also visualized by using PyMol (Fig. 15). The PDBsum of ProFunc server provided the secondary structure of the designed protein which contains 4-helical structures, 1 helix-helix interaction, $13 \beta$ turns, and $2 \gamma$ turns as shown in Fig. 16. It revealed that the S.AMP 13 enzyme contained $21.3 \%$ of $\alpha$-helix, $76.5 \%$ of other structure (coil), and 2.2\% 310 helices. The PROCHECK of the PDBsum server was employed for the evaluation of the stereochemical quality of the designed structure S.AMP13. The topology diagram of the structural domain in S.AMP13 is shown in Fig. 17. Ramachandran plot for the model was shown in Fig. 18 and revealed that $91.5 \%$ of amino acid residues were in the most favored region represented by red patches, $8.5 \%$ of amino acid residues were in the additionally allowed region represented by yellow fields, and there were no residues located in the disallowed regions which are represented by white field. Assessment of Ramachandran plot analysis confirms that the generated model was good in quality.

\section{Discussion}

Serratiopeptidase is an alkaline metalloprotease produced from various sources such as Serratia marcescens, Pseudomonas aeruginosa, Proteus mirabilis, Erwinia chrysanthemi [4, 5], Xenorhabdus [6, 7], Deinococcus radiodurans [8], and Bacillus subtilis [9]. In this present study, the protease of S. hydrogenans var. MGS13 was purified from the optimized medium by following a two-step procedure. In the first step, the supernatant was precipitated with ammonium sulfate followed by gel filtration using Sephadex G-100 (Sigma Aldrich). After gel filtration, the purity of the enzyme was tested with SDS-PAGE, and a single band of $32 \mathrm{kDa}$ was obtained. The molecular mass of the purified metalloprotease obtained from S. hydrogenans var. MGS13 was quite close to the molecular mass of alkaline metalloprotease from Pseudomonas aeruginosa

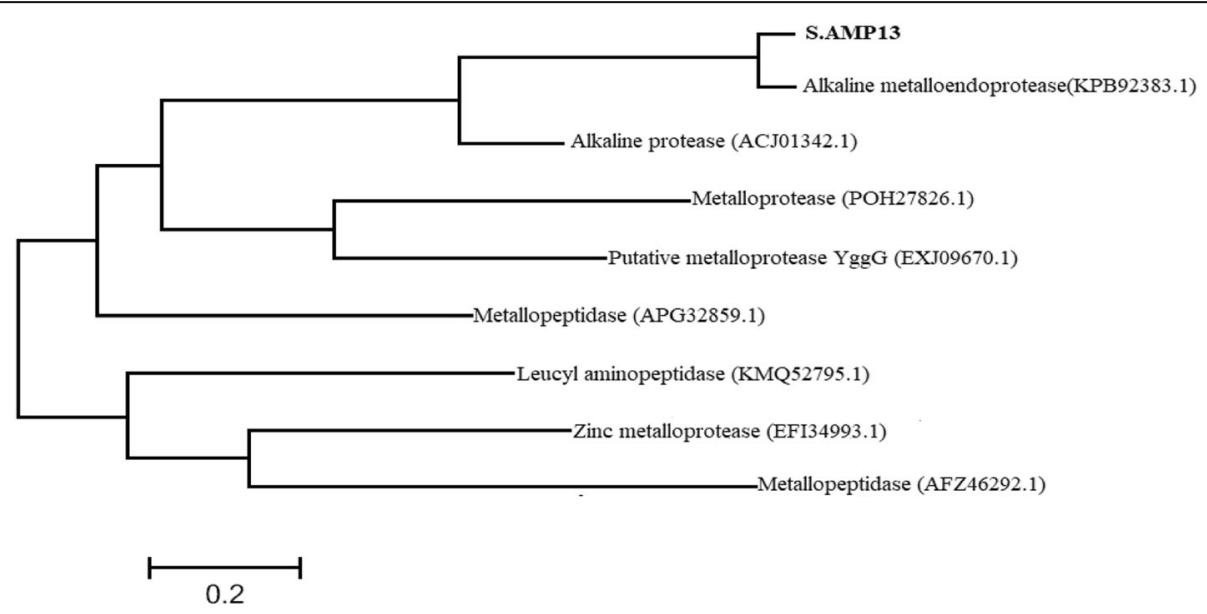

Fig. 11 Phylogenetic tree analysis of S.AMP13 with other metalloproteases 


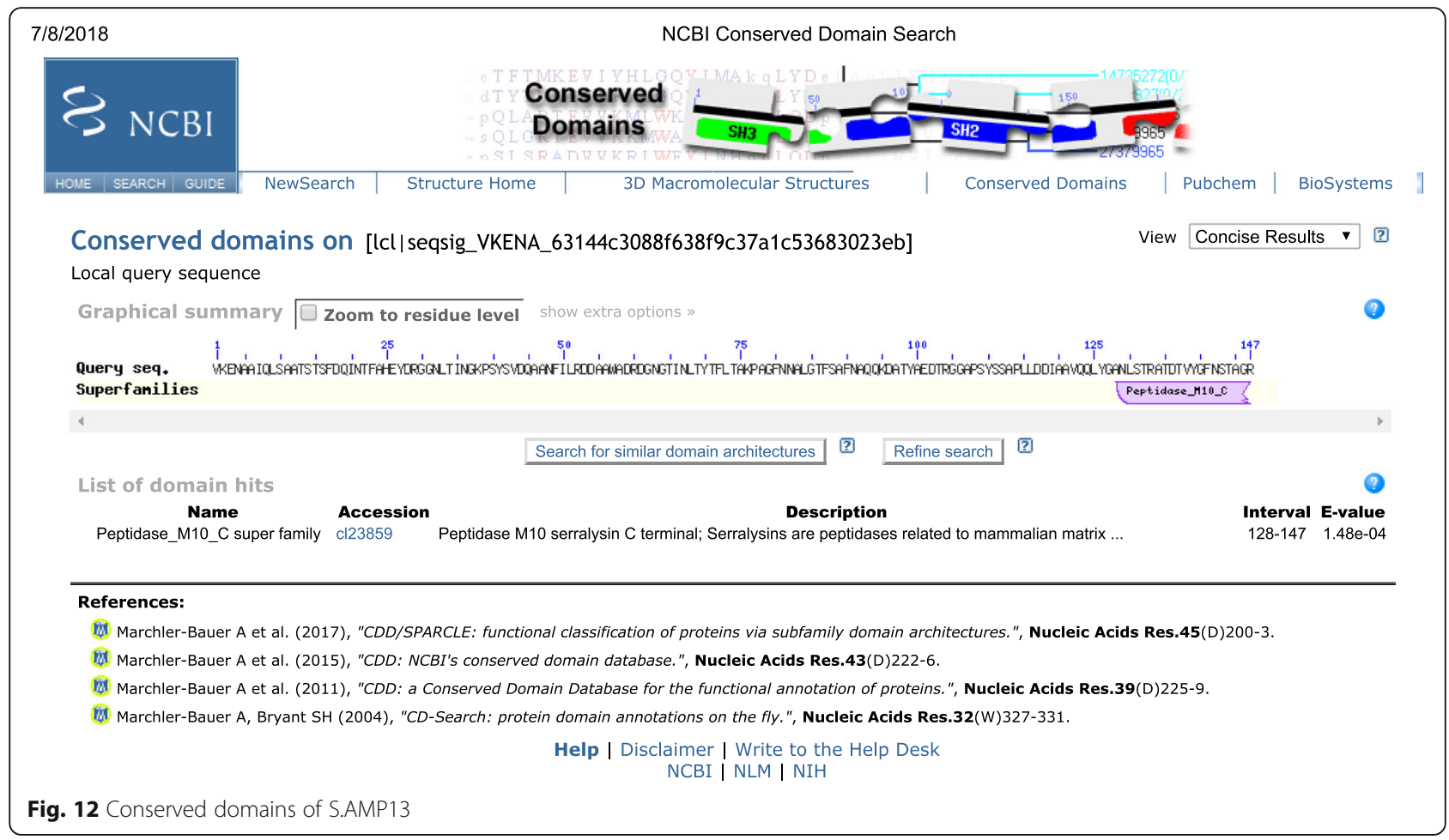

MN1 [24] with a molecular weight of $32 \mathrm{kDa}$. Moreover, this signifies the fact that the mass of the purified enzyme was lower when compared to alkaline metalloprotease obtained from Serratia marcescens [25] and Xenorhabdus indica [7], where the reported molecular weight was between 46 and $60 \mathrm{kDa}$. This result illustrates that the molecular mass of purified protease obtained from the $S$. hydrogenans var. MGS13 was not similar with serratiapeptidase obtained from Serratia marcescens and shows more similarity with serralysin-like alkaline metalloprotease from Pseudomonas. Casein zymogram showed a single hydrolytic band which confirmed that the purified enzyme was a protease. Similar results have been observed in the case of serratiopeptidase obtained from Serratia marcescens [25] and fibrinolytic metalloprotease from Bacillus cereus $\mathrm{B} 80$ [26].

The ideal $\mathrm{pH}$ for the serratiopeptidase activity was found to be $\mathrm{pH} 9.0$ which is similar to the

\section{Motif in the sequence}

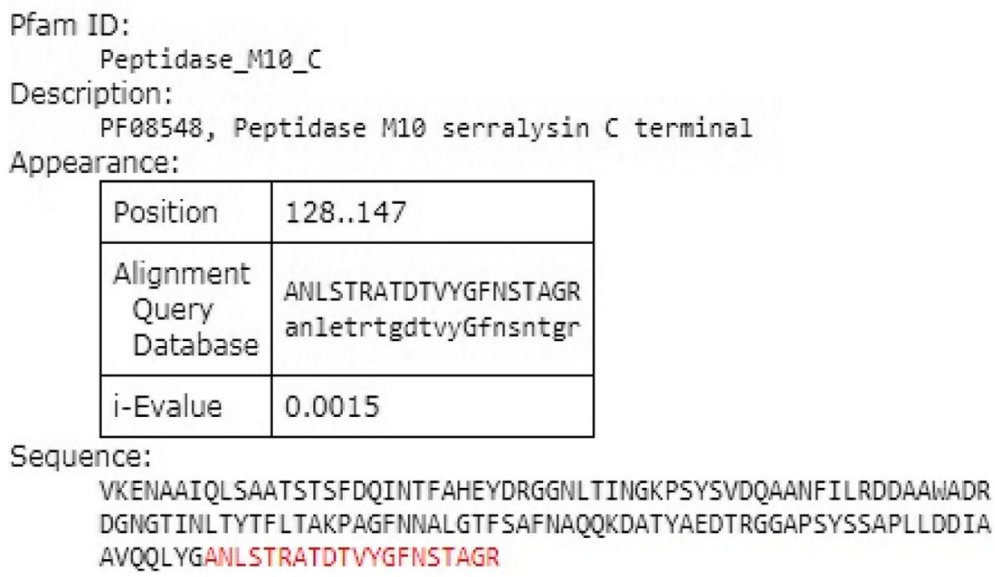

Fig. 13 Motif matches of S.AMP13 


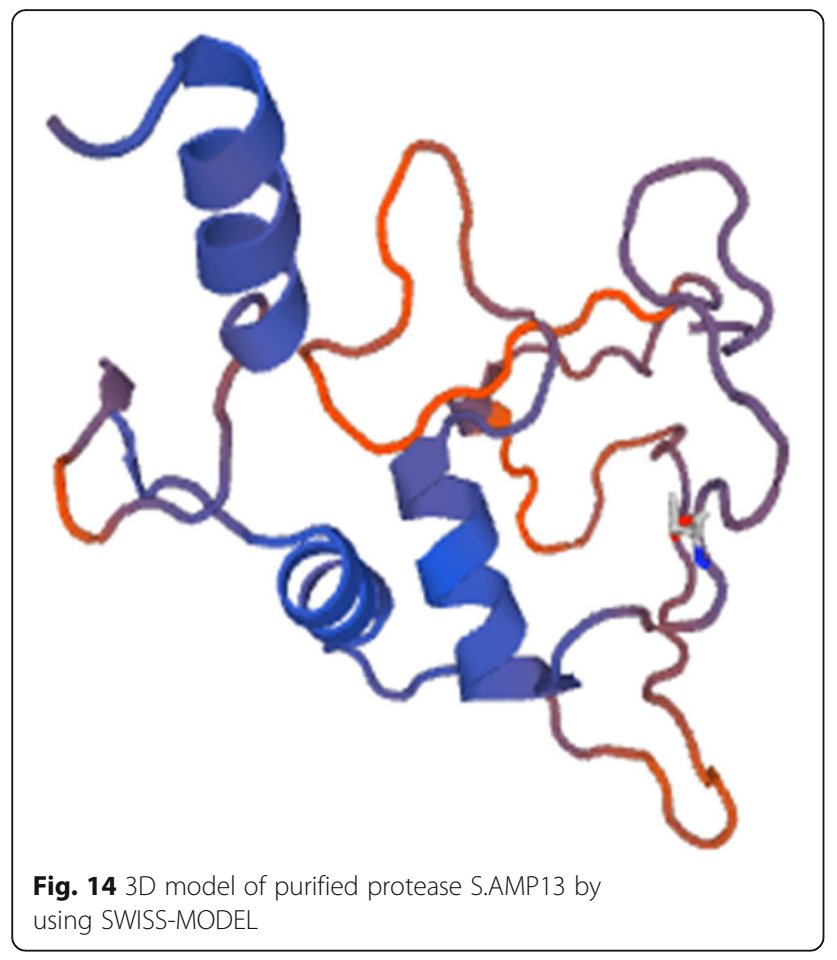

serratiopeptidase obtained from S. marcescens [25] and strongly indicates that the enzyme is alkaline in nature. However, alkaline metalloprotease obtained from Pseudomonas aeruginosa MN1 showed a slight variation where the optimum $\mathrm{pH}$ for the enzyme activity was 8.0 [24]. The purified serratiopeptidase showed a maximum stability between $\mathrm{pH} 7$ and 9, whereas the serratiopeptidase from Serratia sp. RSPB11 [25] showed $50 \%$ of activity at $\mathrm{pH} 6.0-10.0$ and a fibrinolytic metalloprotease

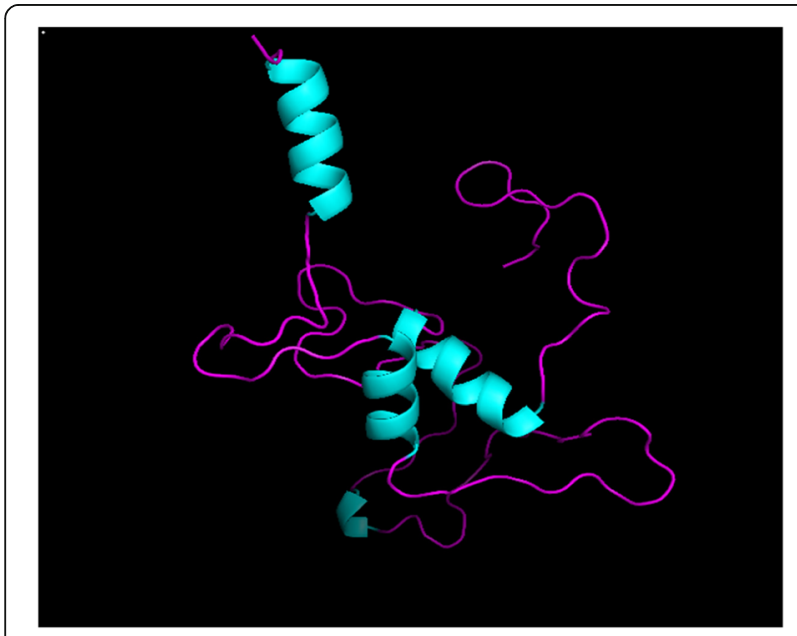

Fig. 15 Visualization of the 3D structure of S.AMP13 by using PyMOL Molecular Graphics System from Bacillus cereus B80 [26] showed maximum stability at $\mathrm{pH}$ 6.0-9.0. These observations indicate the variation existing in the stability of peptidases over different $\mathrm{pH}$ ranges.

The temperature effect on enzyme activity highlights the fact that the reaction environment temperature regulates the serratiopeptidase activity, and it requires an ideal temperature for cleaving the substrate. Similar results were observed in case of alkaline metalloprotease from Serratia sp. RSPB1 [25], Bacillus brevis MWB-01 [27], and Pseudomonas fluorescens 114 [28], where optimum enzyme activity was observed at $37^{\circ} \mathrm{C}, 40^{\circ} \mathrm{C}$, and $35^{\circ} \mathrm{C}$, respectively. In the thermal stability studies, more than $50 \%$ residual activity was noticed at $60^{\circ} \mathrm{C}$, revealing that the protease of $S$. hydrogenans var. MGS13 is moderately thermostable. Similarly, serratiopeptidase obtained from S. marcescens [25] and alkaline metalloprotease obtained from Bacillus cereus B80 [26] retained 50\% of their activities at $50^{\circ} \mathrm{C}$ and $70^{\circ} \mathrm{C}$, respectively.

The impact of different inhibitors on the enzyme activity was evaluated to know the nature of purified protease of S. hydrogenans var. MGS13. PMSF at 1, 5, and $10 \mathrm{mM}$ had little effect on serratiopeptidase activity confirming that the enzyme is not a serine protease, because serine proteases are strongly inactivated by PMSF at a concentration ranging from 0.1 to $1 \mathrm{mM}$ [29]. However, the activity of purified protease was impaired by EDTA indicating that metal ion plays an indispensable role in the catalytic action of an enzyme which is conclusively indicating that this enzyme comes under metalloproteases class. The low inactivation rate caused by $1 \mathrm{mM}$ EDTA (55\%) might have been caused by competition among the excess of metals present at non-active sites. As EDTA concentration increases, the inhibitory effect is also increased, and the maximum inhibition was noticed with $10 \mathrm{mM}$ EDTA. The study was also conducted by casein clearing zone method [22] in order to check the inhibitory effect on the enzyme activity visually. This method allows accuracy, and the hydrolytic zone produced on casein agar could be related to the amount of protease in the sample. The enzyme was strongly inactivated by EDTA than PMSF, thereby a small hydrolytic zone was observed in the presence of EDTA indicating that the purified enzyme is a metalloprotease. This procedure is more desirable for evaluating the change in activity and determines the nature of protease. Further, the increase in activity was also noticed in the presence of $\mathrm{Zn}^{2+}, \mathrm{Na}^{+}$, and $\mathrm{K}^{+}$which illustrates that serratiopeptidase activity was positively regulated by these metal ions at $5 \mathrm{mM}$ concentration. However, the presence of metals like $\mathrm{Mg}^{2+}$ and $\mathrm{Cu}^{2+}$ in the reaction mixture retarded the catalytic activity which is in contrast with serratiopeptidase from Serratia marscens where $\mathrm{Mg}^{2+}$ and $\mathrm{Cu}^{2+}$ enhanced the activity. This kind of variation in activity with the presence of a specific metal ion was 


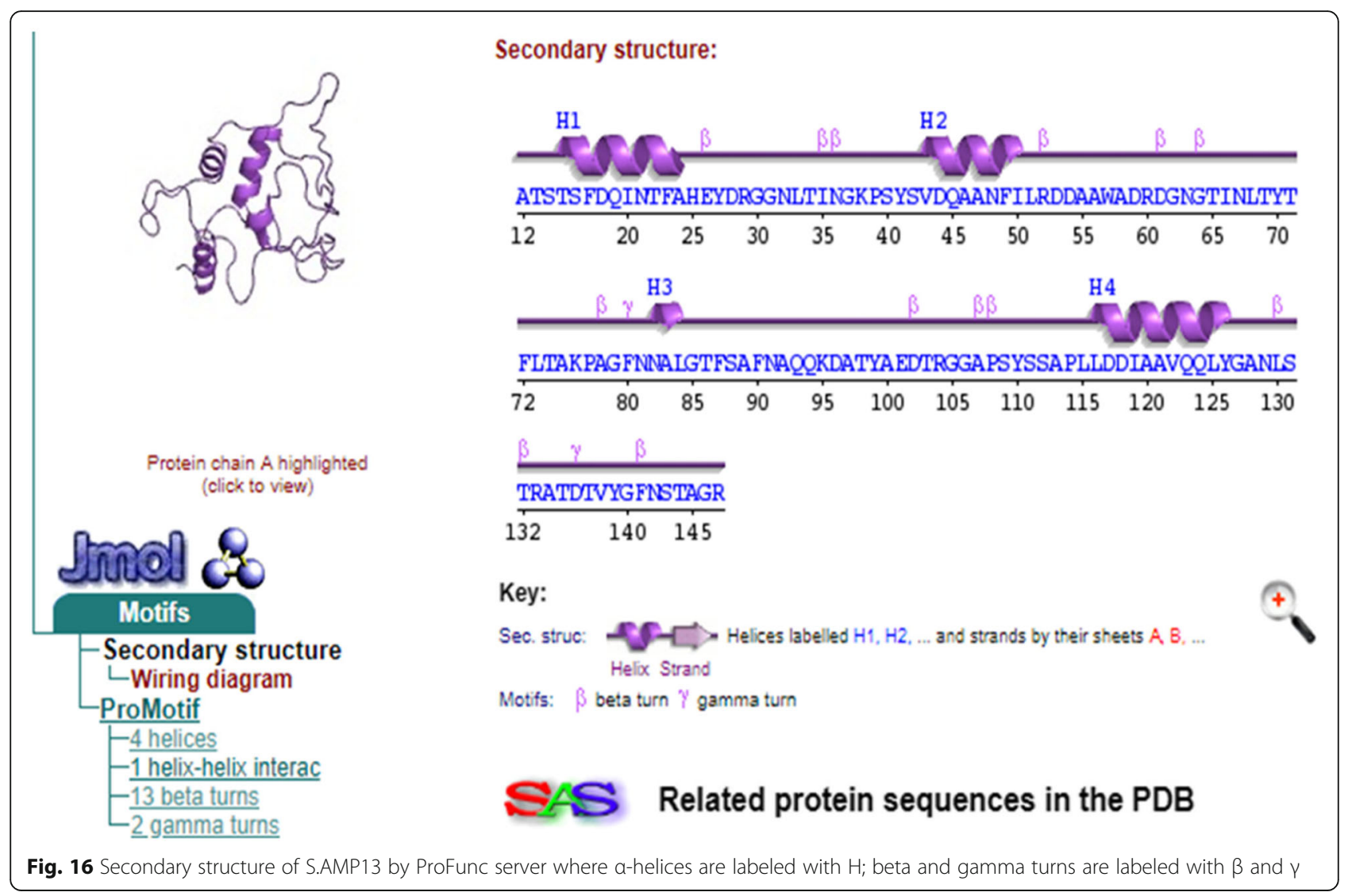

also noticed with metalloprotease from Serratia marscens [25] where $\mathrm{Ca}^{2+}, \mathrm{Co}^{2+}, \mathrm{Cu}^{2+}, \mathrm{K}^{+}, \mathrm{Mg}^{2+}, \mathrm{Na}^{+}$, and $\mathrm{Zn}^{2+}$ increased the enzyme activity. Similar results have also been observed with the protease from Bacillus brevis MWB-01 [27] where the addition of $\mathrm{Ca}^{+2}$

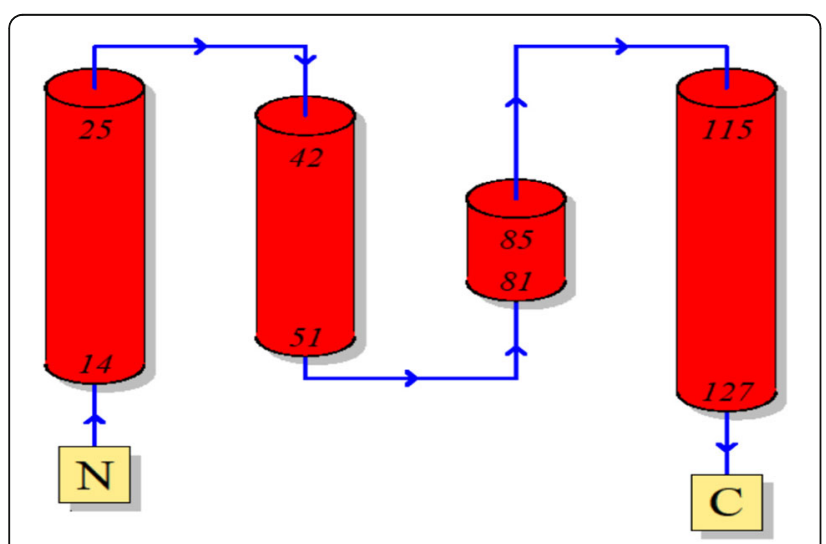

Fig. 17 The topology diagram of the structural domain in S.AMP13. The diagram shows the relative location of the a-helices represented by the red cylinders, and the blue color arrow indicates the directionality of the protein chain from the $\mathrm{N}$ - to C-terminal and $\mathrm{Mn}^{+2}$ enhanced the enzyme activity whereas $\mathrm{Hg}^{2+}$ and $\mathrm{Zn}^{2+}$ retarded the activity.

The specific metal ions such as $\mathrm{Ca}^{2+}, \mathrm{Zn}^{2+}, \mathrm{Na}^{+}$, and $\mathrm{K}^{+}$have significantly regained the metalloprotease activity, and the results were similar with alkaline metalloprotease of Serratia marcescens and Pseudomonas fluorescens [30] where $\mathrm{Ca}^{2+}$ and $\mathrm{Zn}^{2+}$ were effective in regaining the enzyme activity of EDTA inactivated metalloproteases.

The enzyme was excised from the SDS-PAGE gel as a single band and analyzed by LC-MS/MS for peptide mapping. The identification was done using the whole Swiss-Prot database for the species of interest (Streptomyces) and alkaline metalloprotease protein in different species to check the presence of different proteins in the sample with a false determination rate of $4 \%$. The obtained partial amino acid sequence showed the highest homology with an alkaline metalloendoprotease of Pseudomonas syringae pv. maculicola (33769 mol. wt). Similarly, partial amino acid sequence of alkaline metalloprotease obtained from the Pseudomonas aeruginosa showed the highest homology with serralysin protease [30] and in another study, peptide fragments of Xenorhabdus nematophila showed the highest homology with alkaline metalloprotease of 


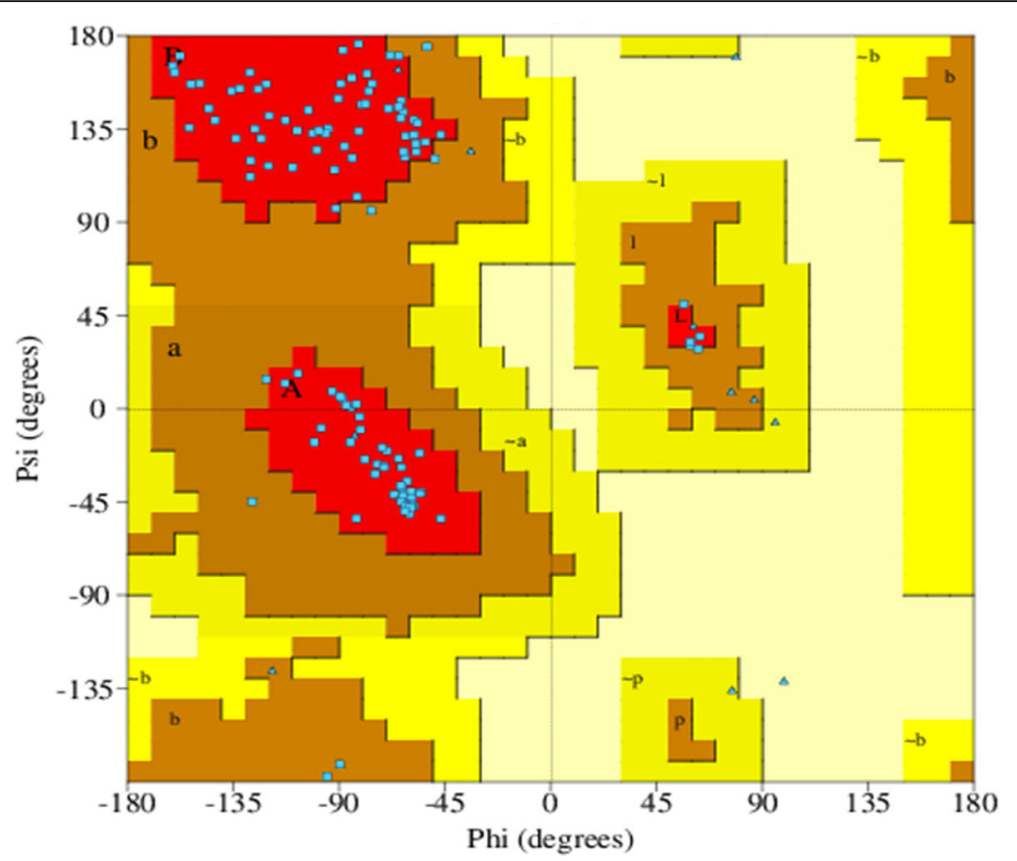

Fig. 18 Ramachandran plot of S.AMP 13 using PROCHECK

Pseudomonas aeruginosa [31]. Phylogenetic analysis revealed that S.AMP13 showed the closest sequence similarity with alkaline metalloprotease of Pseudomonas sp. and in a similar manner, alkaline metalloprotease of Pseudomonas sp. showed sequence similarity with serralysin from Serratia marcescens [32]. The presence of peptide sequence ANLSTRATDTVYGFNSTAGR in the conserved region indicates that this enzyme (S.AMP 13) might be as serralysin-like metalloprotease as shown in Figs. 12 and 13. Similarly, metalloprotease of various sources such as $P$. aeruginosa, E. chrysanthemi, and $S$. marcescens shares a common sequence pattern in the conserved region and can be grouped together as a serralysin family [30]. A 3D model of S.AMP13 was generated using homology modeling, and the quality of that model was ensured as the best model based on the number of residues in most favored and additionally allowed regions.

\section{Conclusions}

The electrophoretic analysis strongly confirmed that the isolated enzyme was a protease, and molecular weight was ascertained around $32 \mathrm{kDa}$. Inhibitor studies and peptide mapping denoted that this enzyme S.AMP13 belongs to metalloprotease. This enzyme S.AMP13 shared a conserved region of serralysin at positions $128-147$ in $\mathrm{C}$-terminal which denotes that the enzyme belongs to the serralysin family. The 3D model of S.AMP13 protein structure was predicted by homology modeling method and structurally validated by PROCHECK server using the Ramachandran plot (Additional files 1 and 2). The present findings suggest that S.AMP13 obtained from $S$. hydrogenans var. MGS13 is a serralysin-like protease, and the properties of this enzyme makes it valuable for the development of anti-inflammatory agent.

\section{Additional files}

Additional file 1: PROCHECK statistics: Ramachandran plot statistics. (PNG 28 kb)

Additional file 2: PROCHECK statistics: G-factors. (PNG 22 kb)

\section{Abbreviations}

ACN: Acetonitrile; BLAST: Basic Local Alignment Search Tool; CDD: Conserved Domain Database; ClustalX: Clustal with a graphical user interface;

D: Dimensional; DTT: Dithiothreitol; EDTA: Ethylene diamine tetra acetic acid; FA: Formic acid; FASTA: Pairwise Alignment Program; HGF: Horse gram flour; IP: Indian Pharmacopoeia; LC-MS: Liquid chromatography and mass spectrometry; MEGA: Molecular Evolutionary Genetic Analysis; NCBI: National Center for Biotechnology Information; PDB: Protein Data Bank;

PLGS: ProteinLynx Global SERVER; PMSF: Phenyl methyl sulphonyl fluoride; QMEAN: Qualitative model energy analysis; Q-TOF: Quadrupole time-of-flight: S.AMP13: Alkaline metalloprotease obtained from S. hydrogenans var. MGS13; SDS: Sodium dodecyl sulfate; SMTL: SWISS-MODEL Template Library; SSF: Solid-state fermentation; SD: Standard deviation; SWISS: Structural Bioinformatics Web Server; UPLC: Ultra-pressure liquid chromatography; var.: Variant; $\beta$ : Beta; $\uparrow:$ Gamma; $\delta$ : Delta

\section{Acknowledgements}

The authors want to acknowledge A.U. College of Pharmaceutical Sciences, Andhra University, for providing laboratory facilities to carry out the entire research work. The authors are also thankful to Dr. M. Murali Krishna, Asst. Professor, A.U. College of Pharmaceutical Sciences, Andhra University; Dr. D. Muni Kumar (Post-Doctoral Fellow), Department of Biochemistry, Andhra University; and $\mathrm{CH}$. Hymavathi, Research Scholar, A.U. College of

Pharmaceutical Sciences, Andhra University, for helping me in the analysis of 
LC-MS/MS data and prediction of the 3D structure of the enzyme. The authors are extremely grateful to T. Prabhakar, Retd. Professor, A.U. College of Pharmaceutical Sciences, for giving valuable suggestions in preparing this manuscript.

\section{Authors' contributions}

SN designed and carried out the entire experimental work, analyzed the data, and wrote the manuscript. GGS supervised the entire work and reviewed the final manuscript. YBL participated in the experimental work and analysis. All authors have read and approved the final manuscript.

\section{Funding}

The entire work was carried out in Andhra University with available resource; some analyses were done with self-funding.

\section{Availability of data and materials}

All data generated or analyzed during this study are included in this published article.

\section{Ethics approval and consent to participate}

Not applicable

\section{Consent for publication}

Not applicable

\section{Competing interests}

The authors declare that they have no competing interests.

Received: 19 July 2019 Accepted: 24 July 2019

Published online: 23 September 2019

\section{References}

1. Rawlings ND, Barrett AJ, Bateman A (2012) MERPOS: the database of proteolytic enzymes, their substrates and inhibitors. Nucleic Acids Res. 40: 343-350

2. Al-Khateeb TH, Nusair Y (2008) Effect of the proteolytic enzyme serrapeptase on swelling, pain and trismus after surgical extraction of mandibular third molars. Int J Oral Maxillofac Surg. 37:264-268

3. Russell LW, Judith SB (1990) Phe5 (4-nitro)-bradykinin: a chemogenic substrate for assay and kinetics of the metalloendopeptidase meprin: Anal. Biochem. 191:314-320. https://doi.org/10.1016/0003-2697(90)90225-X

4. Lakshmi Bhargavi P, Prakasham RS (2012) Proteolytic enzyme production by isolated by isolated Serratia sp RSPB11: role of environmental parameters. Curr Trends Biotechnol Pharm. 6:55-65

5. Wu D, Ran T, Wang W, Xu D (2016) Structure of a thermo stable serralysin from Serratia sp. FS14 at 1.1A resolution. Acta Cryst 72:10-15

6. Massaoud MK, Marokhazi J, Venekei I (2011) Enzymatic characterization of a seralysin-like metalloproteases from the entomopathogen bacterium, Xenorhabdus. Biochimic Biophys Acta. 1814:1333-1339

7. Pranaw K, Surender S, Debjani D, Nipendra S, Garima S, Sudershan G et al (2013) Extracellular novel metalloprotease from Xenorhabdus indica and its potential as an insecticidal agent. J Microbiol Biotechnol 23:1536-1543

8. Basu B, Apte SK (1784) A novel serralysin metalloprotease from Deinococcus radiodurans. Biochem Biophys Acta. 2008:1256-1264

9. Kyostio SR, Cramer CL, Lacy GH (1991) Erwinia carotovora subsp. Carotovora extracellular protease; characterization and nucleotide sequences of the gene. J. Bacteriol. 173:6537-6546

10. MacCabe AP, Polaina J. (2007) Industrial enzymes: structure, function and applications 1st ed. Springer Dordrecht: Netherlands.

11. Kreger AS, Griffin OK (1975) Cornea-damaging proteases of Serrratia marcescens. Invest Ophthalmol. 14:190-198

12. Wang J, Wang M, Wang $Y$ (1998) Purification and characterization of novel fibrinolytic enzymes from Streptomyces sp. Chin J Biotechnol. 15:83-89

13. Uesugi Y, Usuki H, Iwabuchi M, Hatanaka T (2011) Highly potent fibrinolytic serine protease from Streptomyces. Enzyme Microb Technol. 48:7-12

14. Simkhada JR, Mander P, Cho SS, Yoo JC (2015) A novel fibrinolytic protease from Streptomyces sp.CS684. Process Biochem. 45:88-93

15. Jyothi V, Girija Sankar G, Prabhakar T (2014) Isolation of novel mutant strain for enhanced production of extracellular serratiopeptidase from mangrove soil. Int J Pharma Sci Rev Res. 24:302-305
16. Jyothi V, Haritha C, Girija Sankar G, Prabhakar T (2014) Application of response surface methodology in medium components optimization to enhance serratiopeptidase production by S. hydrogenans MGS13. Eur Sci J 10:196-209

17. Deutzmann R (2004) Structural characterization of proteins and peptides. Methods Mol Med. 94:269-297

18. Indian Pharmacopoeial Commission (2010) Indian pharmacopoeia, 6th edn. Govt.of India,Ministry of health and family welfare, Ghaziabad, Delhi, India

19. Lowry OH, Rosebrough NJ, Farr AL, Randall RJ (1951) Protein measurement with Folin reagent. J Biol Chem. 193:265-275

20. Laemmli UK (1970) Cleavage of structural proteins during the assembly of head of bacteriophage T4. Nature. 227:680-685

21. Garcia-Carreno FL, Dimes LE, Haard NF (1993) Substrate gel electrophoresis for composition and molecular weight of proteinase or proteinaceous proteinase inhibitors. Anal Biochem. 214:65-69

22. Katsushi Y, Naomi F, Seiko T (1988) Application of casein agar plate method for determination of protease activity. J J Toxicol Environ Health. 34:241247. https://doi.org/10.1248/jhs1956.34.241

23. Larkin MA, Blackshields G, Brown NP, Chenna R, McGettigan PA (2007) Clustal W and Clustal X version 2.0. Bioinformatics. 23:2947-2948

24. Bayoudh A, Gharsallah N, Chamkha M, Dhouib A, Ammar S, Nasri M (2000) Purification and characterization of an alkaline protease from Pseudomonas aeruginosa MN. J Ind Microbiol Biotech. 24:291-295

25. Bhargavi PL, Prakasham RS (2013) A fibrinolytic, alkaline and thermo stable metalloprotease from the newly isolated Serratia sp. RSPB11. Int J Biol Macromol. 61:479-486. https://doi.org/10.1016/j.ijbiomac.2013.07.009

26. Rajasree S, Rajani S. MALDI-TOF MS and CD spectral analysis for identification and structural prediction of a purified, novel, organic solvent stable, fibrinolytic metalloprotease from Bacillus cereus B80.Bio. Med. Res. Int 2015; Article ID 527015,1-13.

27. Olajuyigbe FM, Faladel MA (2014) Purification and partial characterization of serine alkaline metalloprotease from Bacillus brevis MWB- 01. Bioresour. Bioprocess. 1:8

28. Hamamoto T, Kaneda M, Horikoshi K, Toshiaki K (1994) Characterization of a protease from a psychrotroph, Pseudomonas fluorescens 114. Appl Environ Microbiol. 60:3878-3880

29. Salarizadeh N, Hasannia S, Noghabi NA, Sajedi RH (2014) Purification and characterization of $50 \mathrm{kDa}$ extracellular metalloprotease from Serratia sp. ZF03. Iran J Biotech 12:18-27. https://doi.org/10.15171/ijb.1009

30. Kim HJ, Tamanoue Y, Jeohn GH, Iwamatsu A (1997) Purification and characterization of an extracellular metalloprotease from Pseudomonas fluorescens. J Biochem 121:82-88

31. Caldas C, Cherqui A, Pereira A, Simoes N (2002) Purification and characterization of an extracellular protease from Xenorhabdus nematophila involved in insect immunosuppressant. Appl Environ Microbiol. 68:1297-1304

32. Shanks RM, Stella NA, Hunt KM, Brothers KM, Zhang L, Thibodeau PH (2015) Identification of SlpB, a cytotoxic protease from Serratia marcescens. Infect Immune 83:2907-2916

\section{Publisher's Note}

Springer Nature remains neutral with regard to jurisdictional claims in published maps and institutional affiliations.

\section{Submit your manuscript to a SpringerOpen ${ }^{\circ}$ journal and benefit from:}

- Convenient online submission

- Rigorous peer review

- Open access: articles freely available online

- High visibility within the field

Retaining the copyright to your article

Submit your next manuscript at $>$ springeropen.com 